Article

\title{
Facile Route for Synthesis of Novel Flame Retardant, Reinforcement and Antibacterial Textile Fabrics Coatings
}

\author{
Nour F. Attia 1,2,*(D), Mohamed H. Soliman ${ }^{3}$ and Sahar S. El-Sakka ${ }^{3, *}$ \\ 1 Fire Protection Laboratory, Chemistry Division, National Institute of Standards, Giza 12211, Egypt \\ 2 Department of Energy Engineering, Gyeongnam National University of Science and Technology, \\ Naedong-ro139beon-gil 8, Jinju 52849, Korea \\ 3 Chemistry Department, Faculty of Science, Suez University, Suez 43527, Egypt; \\ Mohamed.Soliman@sci.suezuni.edu.eg \\ * Correspondence: drnour2017@gntech.ac.kr (N.F.A.); Sahar.el-sakka@sci.suezuni.edu.eg (S.S.E.-S.)
}

Received: 31 May 2020; Accepted: 17 June 2020; Published: 19 June 2020

\begin{abstract}
New and innovative textile fabrics coatings were facilely developed. The coating was developed based on synthesis of novel charring and antibacterial organic agent in conjunction with chitosan. $N$-[2,3-dibromo-4-(4-methoxy-3-methylphenyl)-4-oxobutanoyl]anthranilic acid was synthesized as organic antibacterial, reinforcement, and charring agent (OA) and then, dispersed in chitosan solution followed by coating on textile fabrics using immersion route forming new flame retardant coating layer. The developed organic molecule structure was elucidated using spectroscopic techniques. The mass loadings of developed organic agent dispersed in chitosan solution were varied between 20-60 wt.\%. The coated textile fabrics have special surface morphology of fiber shape aligned on textile fibers surface. The thermal stability and charring residues of the coated textile fabrics were enhanced when compared to blank and organic agent free coated samples. Furthermore, the flammability properties were evaluated using LOI (limiting oxygen index) and UL94 tests. Therefore, the coated textile fabrics record significant enhancement in flame retardancy achieving first class flame retardant textile of zero $\mathrm{mm} / \mathrm{min}$ rate of burning and $23.8 \%$ of LOI value compared to $118 \mathrm{~mm} / \mathrm{min}$. rate of burning and $18.2 \%$ for blank textile, respectively. The tensile strength of the coated textile fabrics was enhanced, achieving 51\% improvement as compared to blank sample. Additionally, the developed coating layer significantly inhibited the bacterial growth, recording $18 \mathrm{~mm}$ of clear inhibition zone for coated sample when compared to zero for blank and chitosan coated ones.
\end{abstract}

Keywords: flame retardants; thermal stability; antibacterial; coatings; textile fabrics

\section{Introduction}

Textile-based materials have been used extensively in a variety of applications due to their interesting properties [1]. However, the demand of the textile fabrics for some applications require new smart functions to be included, such as high thermal stability, flame retardancy, and inhibition of the bacterial growth [2-4]. Various materials have been used for improving the thermal stability, flame retardancy, and antibacterial behavior of textile fabrics while using different nanoparticles [57]. However, the tensile strength of the treated textile fabrics was negatively affected due to the inclusion of nanoparticles inside fibers [8]. Therefore, organic agents were synthesized and used as a capping agent for synthesis of nanoparticles to avoid tensile strength failure [8]. Previously, many organic phosphates compounds have been used for imparting thermal stability and flame retardancy properties to textile fabrics [8-10]. Therefore, there are several studies that have been reported for the incorporation of flame retardancy and antibacterial functions for textile fabrics via 
different textile treatments processes [4,5,10-12]. On the other hand, a variety of spherical metal nanoparticles have been reported for enhancing antibacterial properties of textile fabrics, such as silver nanoparticles (AgNPs), $\mathrm{TiO}_{2} \mathrm{NP}$, and $\mathrm{ZnO}$; however, the tensile strength properties of the treated textile fabrics were reduced $[7,9,13,14]$. This is due to the negative impact of treatment process conditions, such as high acidic medium and higher temperatures processing $[7,13]$. Thus, the design and synthesis of novel and potential antibacterial, flame retardant, and reinforcement coating materials for textile fabrics are a much appreciated and required research trend. On the other hand, derivatives of 2-substituted-4H-3,1-benzoxazin-4-one have been attracted significant attention from chemists and pharmacologists because of their broad spectrum in biological activities and antibacterial applications [15-18]. One of the most important features of 4H-3,1-benzoxazinones chemistry is their use as key starting materials for further transformations in the design and synthesis of biologically active compounds [15-21]. The synthetic and biological importance of 4H-3,1-benzoxazinones stemmed from their facile ring-opening of the oxazinone ring with different nucleophiles to give acyclic products, which undergo heterocyclization to give other synthetically and biologically useful compounds. Chalcones are also known as an important class of biologically active compounds [22-24]. Hence, the synthesis of new charring and antibacterial molecules for imparting good flame retardancy and antibacterial properties for textile fabrics is necessity. Therefore, here, a new organic charring molecule was developed and exploited for the first time with chitosan as textile fabric coating and exhibited excellent antibacterial, flame retardant, and reinforcement properties for coated textile fabrics that are superior than previous reported materials $[7,8,10]$. It is noteworthy to note that several methods were used for the coating of textile fabrics using coatings, such as sol-gel [25], layer-by-layer [25], back coating [10], and pad-dry-cure (immersion) [13]. However, the pad-dry-cure method is a much more convenient and cost-effective treatment route when compared to the above-mentioned methods in terms of less reagents being used and short steps acquired for treatment [14,26,27]. It is important to note that our group has long been involved in the development of different antibacterial, flame retardant, and thermal stability materials for different textile fabrics $[4,8,10,28,29]$. In this study, $N$-[2,3-dibromo-4-(4-methoxy-3-methylphenyl)-4-oxobutanoyl]anthranilic acid was developed and elucidated as active antibacterial, flame retardant/charring, and reinforcement agent. The developed material was used with chitosan for coating textile fabrics. The mass loading of developed organic molecule was varied and optimized. The surface morphology of uncoated and coated textile fabrics was studied. The tensile strength, thermal stability, flammability, and antibacterial properties were investigated.

\section{Experimental Section}

\subsection{Materials}

Commercial final (dyed) furniture textile fabrics composed from polyester/microfilament/fibran/wool $35 \% / 25 \% / 25 \% / 15 \%$, respectively, were purchased from $\mathrm{Al}$ Mahalla Co., Algharbia, Egypt. Anthranilic acid and all chemicals and solvents used were purchased from El Gomhoria Company of chemicals, Cairo, Egypt. Deionized water (DI) was used in the synthesis of coating systems.

\subsection{Synthesis of 2-[3-(4-methoxy-3-methylphenyl)-3-oxoprop-1-enyl]-4H-3,1-benzoxazin-4-one}

$\mathrm{N}$-[4-(4-methoxy-3-methylphenyl)-4-oxo-2-butenoyl]anthranilic acid (starting material (SM)) was prepared based on reported methods [30,31]. However, 2-[3-(4-methoxy-3-methylphenyl)-3-oxoprop-1-enyl]-4H-3,1-benzoxazin-4-one was synthesized, as follows: a mixture of (1 g) N-[4(4-methoxy-3-methylphenyl)-4-oxo-2-butenoyl]anthranilic acid (SM) and $5 \mathrm{~mL}$ of acetic anhydride were refluxed for $30 \mathrm{~min}$. The obtained precipitate after cooling was filtered off, washed with benzene, and then dried. It was then, crystallized from toluene to produce 2-[3-(4-methoxy-3-methylphenyl)-3-oxoprop-1-enyl]-4H-3,1-benzoxazin-4-one. 


\subsection{Synthesis of N-[2,3-dibromo-4-(4-methoxy-3-methylphenyl)-4-oxobutanoyl]anthranilic acid (OA)}

A solution of $(0.005 \mathrm{~mol})$ bromine in $(20 \mathrm{~mL})$ acetic acid was added dropwise in a solution of 2-[3-(4-methoxy-3-methylphenyl)-3-oxoprop-1-enyl]-4H-3,1-benzoxazin-4-one (0.8 g, $0.0025 \mathrm{~mol})$ in acetic acid $(20 \mathrm{~mL})$. The reaction mixture was stirred at room temperature for $2 \mathrm{~h}$ then kept overnight. Subsequently, the obtained precipitate was filtered off, washed with diluted acetic acid, and crystallized from acetic acid to give (N-[2,3-dibromo-4-(4-methoxy-3-methylphenyl)-4-oxobutanoyl]anthranilic acid.

\subsection{Synthesis Coating Composite for Furniture Textile Fabrics (CH-OA)}

In a glass beaker containing $50 \mathrm{~mL}$ of DI water with 2 vol.\% acetic acid, $1 \mathrm{~g}$ of chitosan was dissolved forming chitosan solution of $2 \mathrm{wt} . \%$. In the prepared ( $2 \mathrm{wt} . \%)$ chitosan solution, variable mass loadings of OA were dispersed using ultrasonication for $10 \mathrm{~min}$. This process gives rise to 20,50 and $60 \mathrm{wt} . \%$ of OA based on final composite mass, as depicted in Table 1. This is in addition to the pure chitosan solution free of OA.

Table 1. Composition of developed coating layer.

\begin{tabular}{cccc}
\hline Sample Code & $\begin{array}{c}\text { Chitosan Mass Loading (CH) } \\
(\mathbf{w t .} \%)\end{array}$ & $\begin{array}{c}\text { Organic Agent Mass Loadings (OA) } \\
(\mathbf{w t .} \%)\end{array}$ & $\begin{array}{c}\text { Add On } \\
(\mathbf{\%})\end{array}$ \\
\hline T & 0 & 0 & 0 \\
CH-T & 100 & 0 & 10 \\
T-CH-OA-20 & 80 & 20 & 15 \\
T-CH-OA-50 & 50 & 50 & 20 \\
T-CH-OA-60 & 40 & 60 & 20 \\
\hline
\end{tabular}

\subsection{Treatment of Furniture Fabrics with Coating Layer ( $\mathrm{T}-\mathrm{CH}-\mathrm{OA}$ )}

In $100 \mathrm{~mL}$ beaker containing chitosan coating dispersion with $\mathrm{OA}$ of $0,20,50$, and $60 \mathrm{wt} . \%$ individually, textile fabrics of $20 \mathrm{~cm} \times 20 \mathrm{~cm}$ dimension were immersed and squeezed individually and then curried at $130{ }^{\circ} \mathrm{C}$ for $10 \mathrm{~min}$. The immersion and curing steps were repeated twice. Finally, different textile composites were obtained, as depicted in Table 1 and denoted as $\mathrm{T}-\mathrm{CH}-\mathrm{OA}-\mathrm{X}$, as $\mathrm{T}$ refers to textile fabrics and $\mathrm{CH}$ for chitosan, $\mathrm{OA}$ refers to developed organic agent, and $\mathrm{X}$ refers to the concentration of OA by wt.\%.

\subsection{Characterization}

${ }^{1} \mathrm{H}$ NMR spectra were measured using Bruker (300 MHz, DMSO, San Jose, CA, USA) and TMS was used as the internal standard. A FT-IR spectrum was obtained using a Perkin Elmer 1430 ratio recording infrared spectrophotometer (Perkin Elmer, MA, USA). A mass spectrum was measured by a GC-MSQP 1000EX Schimadzu (Schimadzu, Kyoto, Japan). The SEM images were taken using a scanning electron microscope (Quanta FEG-250, Thermo Scientific, OR, USA). The tensile strength was tested using tensile testing machine model H1-5KT/S. Thermogravimetric (TGA) analysis was evaluated using TGA 50 (TA Shimudzu Inc., Kyoto, Japan) from room temperature to $550{ }^{\circ} \mathrm{C}$ using nitrogen flow of $100 \mathrm{~mL} \cdot \mathrm{min}^{-1}$ and the heating rate used was $10^{\circ} \mathrm{C} \cdot \mathrm{min}^{-1}$. The antibacterial activity of samples against staphylococcus aureusbacteria was investigated using the AATCC test method 147-2004 [32]. The antibacterial inhibition zone was measured by the average clear inhibition zone of five replicates based on equation $\mathrm{W}=(\mathrm{T}-\mathrm{D}) / 2$. As, $\mathrm{W}$ is the width of the clear inhibition zone in $\mathrm{mm}$ and $\mathrm{T}$ is the total diameter of both test specimen and clear zone in $\mathrm{mm}$ and $\mathrm{D}$ is the width of the test specimen itself in $\mathrm{mm}[29,32]$. The flammability properties of the blank and different coated textile fabrics were studied while using a Fire Testing Technology UL94 flame chamber according to modified ISO $3795[4,8,10,28,33]$. The flame retardant performance were evaluated in terms of rate of burning B in $\mathrm{mm} / \mathrm{min}$. Additionally, the flammability properties were further investigated using a Fire Testing Technology limiting oxygen index instrument (LOI) (\%). 


\section{Results and Discussion}

\subsection{Structural Characterization of Developed Organic Agent (OA)}

\subsubsection{2-[3-(4-methoxy-3-methylphenyl)-3-oxoprop-1-enyl]-4H-3,1-benzoxazin-4-one (2)}

The key starting material, 2-[3-(4-methoxy-3-methylphenyl)-3-oxoprop-1-enyl]-4H-3, 1-benzoxazin-4-one (2) was synthesized in a good yield by the cyclization reaction of $N$-[4-(4-methoxy-3-methylphenyl)-4-oxo-2-butenoyl]anthranilc acid (1) with acetic anhydride, as depicted in Scheme 1.<smiles>COc1ccc(C(=O)/C=C/C(=O)Nc2ccccc2C(=O)O)cc1C</smiles>

(1)<smiles>COc1ccc(C(=O)/C=C/c2nc3ccccc3c(=O)o2)cc1C</smiles>

(2)

Scheme 1. Representation of chemical synthesis of 2-[3-(4-methoxy-3-methylphenyl)-3-oxoprop-1-enyl]-4H-3, 1-benzoxazin-4-one (2).

The structure of compound (2) was elucidated while using spectral and elemental analysis. The FT-IR spectrum of this compound exhibited the characteristic absorption bands of compound (2), as indicated in Figure S1a. Hence, the peak observed at $1660 \mathrm{~cm}^{-1}$ corresponds to vibration of $\mathrm{C}=\mathrm{O}$ of $\alpha, \beta$ unsaturated carbonyl, and the peak situated at $1769 \mathrm{~cm}^{-1}$ is attributed to $\mathrm{C}=\mathrm{O}$ of benzoxazinone ring. Furthermore, the peaks located at $2850-2919 \mathrm{~cm}^{-1}$ are assigned to stretching vibration of C-H aliphatic. The ${ }^{1} \mathrm{H}-\mathrm{NMR}$ spectrum showed the appearance of two singlets in the aliphatic regions at $2.23 \mathrm{ppm}$ and $3.90 \mathrm{ppm}$, which are characteristic for $\mathrm{Ar}-\mathrm{CH}_{3}$ and $\mathrm{Ar}-\mathrm{OCH}_{3}$, respectively. However, the observed multiplets are attributed to the olefinic and aromatic protons appeared between 7.05 and $8.18 \mathrm{ppm}$, respectively (Figure S1b).

3.1.2. $N$-[2,3-dibromo-4-(4-methoxy-3-methylphenyl)-4-oxobutanoyl]anthranilicacid (Organic Agent: OA)

Actually, attempts to synthesize the 2-[2,3-dibromo-3-(4-methoxy-3-methylphenyl)-3-oxopropyl]$4 \mathrm{H}-3,1$-benzoxazin-4-one through the reaction of the benzoxazinone (2) with bromine in different solvent failed to give the desired product. However, the treatment of benzoxazinone (2) with bromine in acetic acid or methylene chloride afforded the $N$-[2,3-dibromo-4-(4-methoxy-3-methylphenyl)-4-oxobutanoyl]anthranilc acid (3) (OA), as shown in Figure 1. 
<smiles>COc1ccc(C(=O)/C=C/C(=O)c2cc(C(=O)/C=C/C(=O)Nc3ccccc3C(=O)O)ccc2OC)cc1C</smiles>

Figure 1. Chemical structure illustration representing the synthesis of N-[2,3-Dibromo-4-(4-methoxy-3-methylphenyl)-4-oxobutanoyl]anthranilic acid (3) (OA).

The proposed structure of this compound was supported by the identity of its melting point with that of an authentic sample prepared by the treatment of the $N$-[4-(4-methoxy-3-methylphenyl)-4-oxo-2-butenoyl] anthranilc acid (1) with bromine in acetic acid. The structure of compound (3) was elucidated by spectroscopic techniques as shown in Figure S2. Figure S2a represents the FT-IR spectra of compound (3) revealed the absence of the absorption bands corresponding to the carbonyl group of the benzoxazinone ring. In addition, the absorption band of carbonyl group of the side chain was observed at $1659 \mathrm{~cm}^{-1}$. Moreover, the absorption bands characteristic for $\mathrm{O}-\mathrm{H}$ and $\mathrm{N}-\mathrm{H}$ groups were observed at 3287 and $3206 \mathrm{~cm}^{-1}$, respectively. The ${ }^{1} \mathrm{H}-\mathrm{NMR}$ spectra (DMSO- $\mathrm{d}_{6}$ ) showed the appearance of two singlets in the aliphatic regions observed at $2.23 \mathrm{ppm}$ and $3.92 \mathrm{ppm}$ which is characteristic for $\mathrm{Ar}-\mathrm{CH}_{3}$ and $\mathrm{Ar}-\mathrm{OCH}_{3}$, respectively (Figure S2b). The signals assigned to the $\mathrm{CO}-\mathrm{C}-\mathrm{H}-\mathrm{Br}-\mathrm{C}-\mathrm{H}-\mathrm{Br}-\mathrm{CO}$ protons were observed as two doublets at 5.22-5.25 and 5.98-6.01 ppm. The multiplets attributed for the aromatic protons appeared between 7.11 and 8.19 ppm as shown in Figure S2b. The signal for $\mathrm{N}-\mathrm{H}$ group was observed as singlet at 11.33 ppm. Furthermore, a broad signal over 12 ppm was attributed to the O-H group. The mass spectrum depicted in Figure S2c showed the molecular ion peak at $m / z 499(0.9 \%)$ which is consistent with its molecular formula $\mathrm{C}_{26} \mathrm{H}_{23} \mathrm{~N}_{5} \mathrm{O}_{2}$ (499.15). Furthermore, the molecular ion underwent suggested fragmentation as shown in the following pattern as shown in Figure S3.

\subsection{Characterization of Developed Coated Textile Fabrics}

Furniture textile fabrics were coated with chitosan layer of $2 \mathrm{wt}$ \% producing T-CH. Subsequently, variable mass loadings of developed OA were individually dispersed via ultrasonication, producing 20, 50, and 60 wt.\% of CH-OA based on the final mass of final composite (Table 1). Afterwards, the produced composites were coated on textile fabrics surface, denoted generally as T-CH-OA. The surface morphology of uncoated and coated textile fabrics was investigated using SEM. Figure 2a represents the blank uncoated surface of textile fabrics, which reflects smooth surface of untreated fibers. In contrast, when chitosan chains were coated on the fabrics, the surface becomes rough, reflecting the coating layer of chitosan chains of $\mathrm{T}-\mathrm{CH}$ composite (Figure $2 \mathrm{~b}$ ). This coating layer was clarified in high magnification SEM image (Figure 2c). Interestingly, when OA was incorporated on chitosan coating layer through dispersion with aid of ultrasonication process, the coating layer was found to be in fiber shape, as indicated on SEM images shown in Figure 2d,e of the T-CH-OA-50 composite. These fibers were aligned on textile fiber surface, as indicated by arrows (Figure 2d,e). 
This fiber shape of coating might be formed during the ultrasonication process for dispersion OA in chitosan solution.
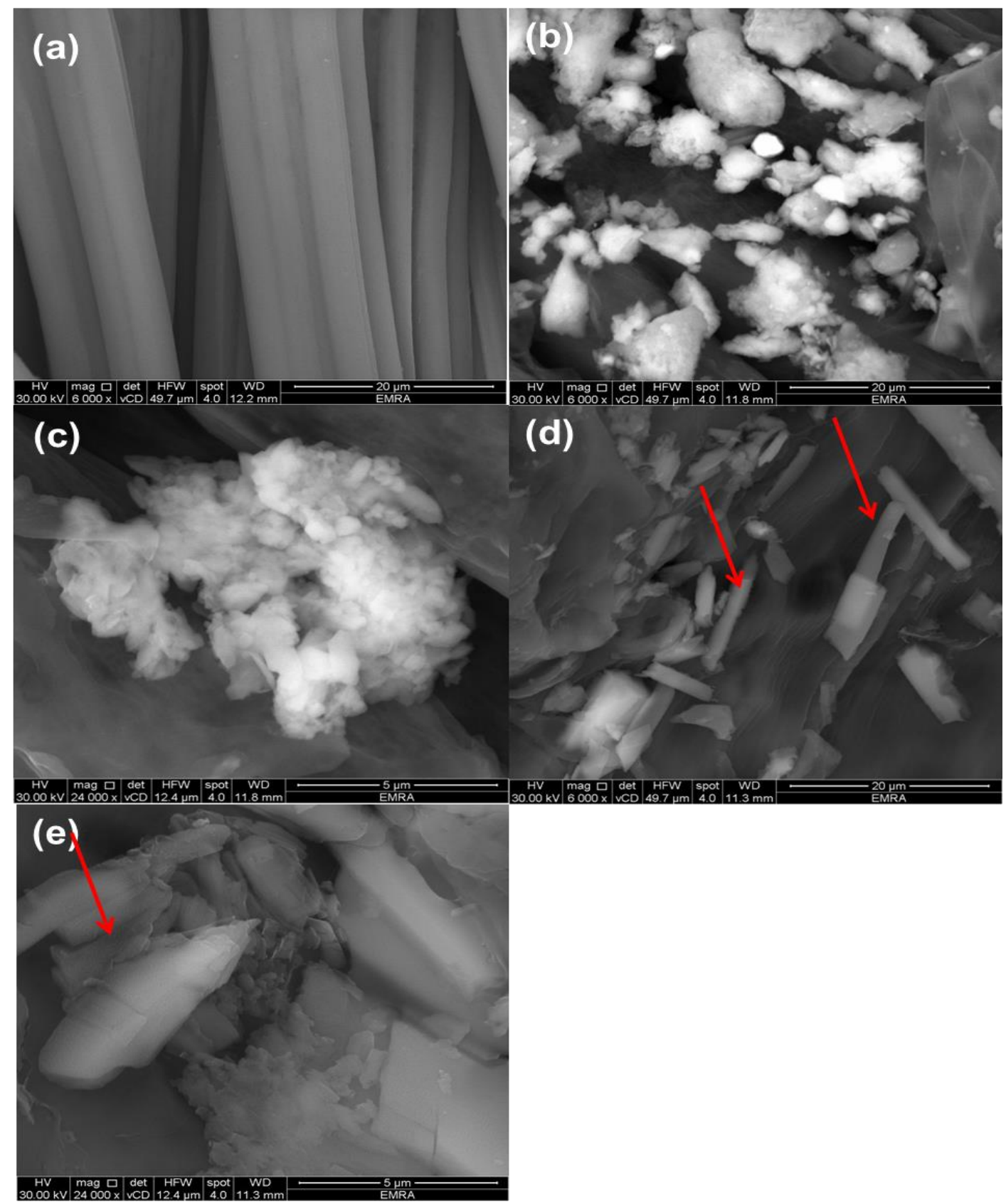

Figure 2. SEM images of (a) Blank Textile (T), (b) Textile coated with chitosan (T-CH), (c) T-CH at high magnification, (d) Textile coated with chitosan and organic agent $50 \mathrm{wt}$ \% (CH-T-OA-50), and (e) CH-T-OA-50 at high magnification.

\subsection{Thermal Stability and Flammability Properties}

On the other hand, thermogravimeteric analysis of untreated and treated textile fabrics gives a clear indication of the effect of $\mathrm{OA}$ on thermal stability and charring tendency of coated textile fabrics. Figure 3a shows the thermogram of uncoated sample, which has an initial mass loss that started at $280{ }^{\circ} \mathrm{C}$ (onset decomposition temperature) due to the decomposition of cellulose chains of fibran and wool chains. However, the main mass loss due to the decomposition of polyester and microfilament chains started at $391{ }^{\circ} \mathrm{C}$ [4]; moreover, the temperatures at $20 \%$ and $50 \%$ mass losses were found to 
be 325 and $414{ }^{\circ} \mathrm{C}$, respectively, and leaving a char residues of $14 \%$ at $550{ }^{\circ} \mathrm{C}$, as indicated in Table 2 . However, for coated samples, similar thermal behavior was noticed; however, the temperature of main mass loss was improved from $393^{\circ} \mathrm{C}$ in T-CH and reached $397^{\circ} \mathrm{C}$ in $\mathrm{T}-\mathrm{CH}-\mathrm{OA}-50$, as indicated in Figure $3 \mathrm{~b}-\mathrm{d}$ and Table 2 . It was noteworthy to note that the thermal stability was enhanced as OA mass loading incorporated in coating layer was increased (Figure 3c,d and Table 2), achieving higher decomposition temperature at $50 \%$ mass loss for $\mathrm{T}-\mathrm{CH}-\mathrm{OA}-50$ when compared to $\mathrm{T}-\mathrm{CH}-\mathrm{OA}-20$, $\mathrm{T}-\mathrm{CH}$, and blank samples. Interestingly, the char residue was also enhanced and the char residues recording 17.2 and $18 \%$ in $\mathrm{T}-\mathrm{CH}-\mathrm{OA}-20$ and $\mathrm{T}-\mathrm{CHOA}-50$, respectively, as compared to $14.7 \%$ and $14 \%$ in T-CH and blank samples respectively (Figure 3 and Table 2). This is indicated that the inclusion of $\mathrm{OA}$ in coating layer induces the textile fabrics for forming char barrier during combustion process yielding good charring effect. This behavior was due to the nitrogen contained structure of OA. Additionally, the influence of formed char barrier was clearly noticed at the main decomposition step as indicated in point A in Figure 3 which shifts the decomposition temperature to higher one (397 ${ }^{\circ} \mathrm{C}$ ) for T-CH-OA-50. Additionally, the ability of T-CH-OA-50 for forming high char residue was also noticed after decomposition of textile fabrics as indicated in point B on Figure 3. On the other hand, the flame retardancy performance for blank and coated textile fabrics samples were evaluated using rate of burning test (UL94) according to modified ISO 3795 standard $[4,8,10,28]$ and also further evaluated using LOI test (Table 3). The flame retardancy behavior was significantly improved when considerable mass loading of new charring molecule was incorporated in the textile coatings. The rate of burning of virgin textile was found to be $118 \mathrm{~mm} / \mathrm{min}$.; however, once $20 \mathrm{wt} . \%$ of OA was incorporated in the coating layer, the rate of burning was reduced to $45 \mathrm{~mm} / \mathrm{min}$. in T-CH-OA-20. Interestingly, when $50 \mathrm{wt} . \%$ was introduced in textile coating, zero rate of burning was achieved for T-CH-OA-50 sample achieving first class flame retardant textile fabrics [28]. This flame retardancy behavior was corroborated by achieving LOI value of $23.8 \%$ for $\mathrm{T}-\mathrm{CH}-\mathrm{OA}-50$ as compared to $18.2 \%$, $19.3 \%$, and $21 \%$ for blank, free OA, and $20 \mathrm{wt} . \%$ contained coated samples, respectively. This affirms the char layer formed was strong enough to afford protective layer upon burning of coated textile fabrics retarding the heat and mass transfer process and, hence, isolating textile flaming layer from burning ones $[8,10]$. Noteworthy to note that, the flame retardancy behavior of developed textile coated sample $\mathrm{T}-\mathrm{CH}-\mathrm{OA}-50$ was found to be superior than previous reported coatings for this purpose $[9,34]$

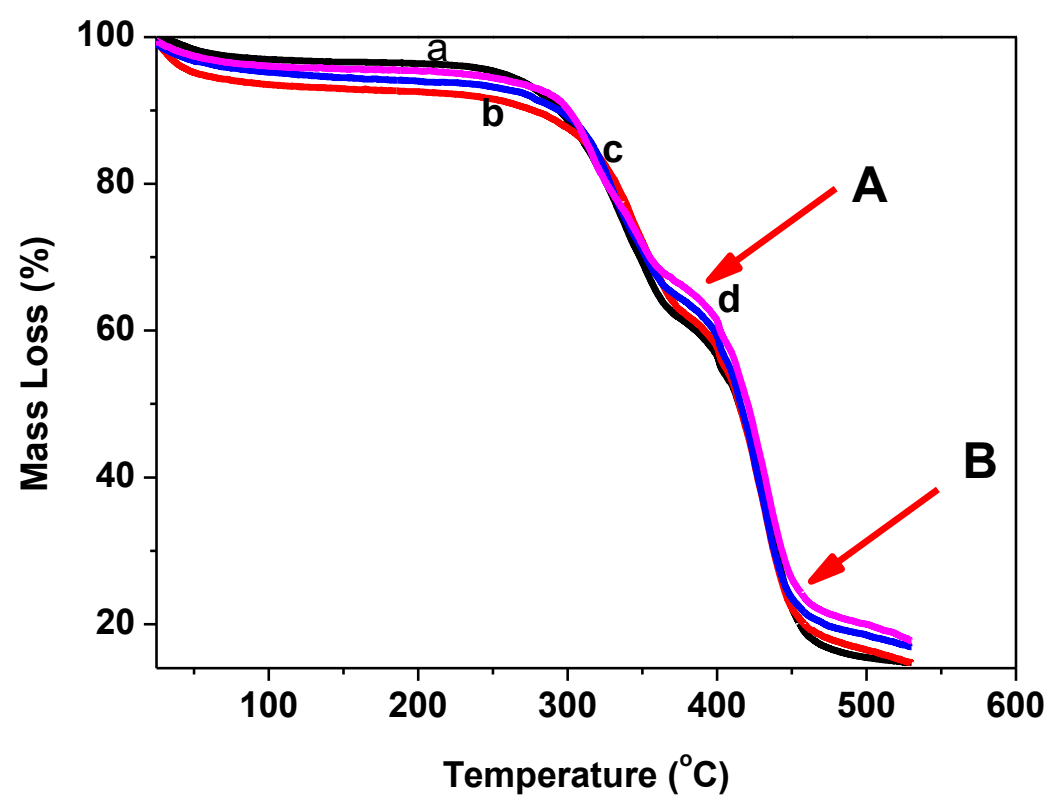

Figure 3. Thermogravimetric analysis (TGA) graphs of (a) Blank textile, (b) T-CH, (c) T-CH-OA-20, and (d) T-CH-OA-50. 
Table 2. Thermal characteristic and flammability data for uncoated and coated samples.

\begin{tabular}{ccccc}
\hline Sample Code & (a) $\mathbf{T}_{\mathbf{2 0} \%} /{ }^{\circ} \mathbf{C}$ & (b) $\mathbf{T}_{\mathbf{~ o n} /{ }^{\circ} \mathbf{C}}$ & (c) $\mathbf{T}_{\mathbf{5 0} \% /{ }^{\circ} \mathbf{C}}$ & (d) Char Residue wt. $\%$ \\
\hline Blank & 325 & 391 & 414 & 14 \\
T-CH & 339 & 393 & 420 & 14.7 \\
T-CH-OA-20 & 325 & 395 & 415 & 17.2 \\
T-CH-OA-50 & 330 & 397 & 423 & 18 \\
\hline
\end{tabular}

(a) Temperature ${ }^{\circ} \mathrm{C}$ at $20 \%$ mass loss, ${ }^{\text {(b) }}$ onset decomposition temperature of main peak, ${ }^{(c)}$ temperature at $50 \%$ mass loss and ${ }^{(\mathrm{d})}$ char residue at $5500^{\circ} \mathrm{C}$.

Table 3. Flammability data for uncoated and coated samples.

\begin{tabular}{ccc}
\hline Sample Code & $\begin{array}{c}\text { Rate of Burning } \\
(\mathbf{m m} / \mathbf{m i n})\end{array}$ & $\begin{array}{c}\text { LOI } \\
\mathbf{( \% )}\end{array}$ \\
\hline Blank & 118 & 18.2 \\
T-CH & 90 & 19.3 \\
T-CH-OA-20 & 45 & 21 \\
T-CH-OA-50 & 0 & 23.8 \\
\hline
\end{tabular}

\subsection{Mechanical and Antibacterial Properties of Developed Textile Fabrics}

The effect of coating on the tensile strength properties of the developed fabrics was evaluated, as tabulated in Table 4. The tensile strength of the untreated sample was found to be $535 \mathrm{~N}$ with elongation of $29 \%$. While, when chitosan layer was coated, the tensile strength of $\mathrm{T}-\mathrm{CH}$ was increased to $759 \mathrm{~N}$, with a reduction in elongation (Table 4). However, when OA was introduced in the coating the tensile strength was also increased recoding $626 \mathrm{~N}$ in T-CH-OA-20. Interestingly, when OA mass loading was further increased in $\mathrm{T}-\mathrm{CH}-\mathrm{OA}-50$, the tensile strength was further enhanced, achieving $51 \%$ and $7 \%$ improvement as compared to blank and $\mathrm{T}-\mathrm{CH}$ samples, respectively (Table 4). It is noted that the tensile strength was found to be $782 \mathrm{~N}$, along with $15.7 \%$ elongation for T-CH-OA-60, which is superior when compared to $\mathrm{T}-\mathrm{CH}$ and $\mathrm{T}$. This enhancement in tensile strength was attributed to the special fiber shape effect of $\mathrm{CH}-\mathrm{OA}$ coating, which aligned on the fabrics fiber surface strengthen their yearn and, hence, reinforced their strength.

Table 4. Mechanical properties of uncoated and coated textile samples.

\begin{tabular}{ccc}
\hline Sample Code & Tensile Strength (N) & Elongation (\%) \\
\hline Blank & $535 \pm 4$ & $29 \pm 1.4$ \\
T-CH & $759 \pm 3$ & $6 \pm 0.4$ \\
T-CH-OA-20 & $625 \pm 44$ & $8 \pm 1.6$ \\
T-CH-OA-50 & $811 \pm 44$ & $12 \pm 4$ \\
T-CH-OA-60 & $782 \pm 23$ & $16 \pm 4$ \\
\hline
\end{tabular}

On the other hand, the developed OA exhibited good antibacterial behavior for treated textile fabrics. The antibacterial properties of the treated and untreated textile fabrics have been tested against staphylococcus aureus bacteria. The untreated, $\mathrm{T}-\mathrm{CH}$, and $\mathrm{T}-\mathrm{CH}-\mathrm{OA}-20$ samples exhibited no antibacterial effect, as indicated in Figure 4. However, when the mass loading of OA incorporated in coating layer was increased in T-CH-OA-50 the antibacterial effect was observed recording $12.3 \mathrm{~mm}$ of clear inhibition zone. Interestingly, a further increase of OA mass loading attributed to positive enhancement in the antibacterial effect achieving $18 \mathrm{~mm}$ of clear inhibition zone (Figure 4 and Table 5). This clarified that OA has a potential effect for inhibition of the growth of bacterial cells (Table 5). It is important to note that the OA was found to be not only good charring agent, but also good reinforcement, flame retardant, and potential antibacterial material. Thus, the treated textile fabrics can be used in various applications, achieving the required comfortability demanded by users. It is noteworthy to note that the antibacterial property of the developed $\mathrm{T}-\mathrm{CH}-\mathrm{OA}-50$ was found to be 
superior to various reported textile fabrics coatings [7,8,34,35]. Interestingly, the coated textile fabrics were found to be stable against washing process for more than few tens washing cycles affirms the durability properties.

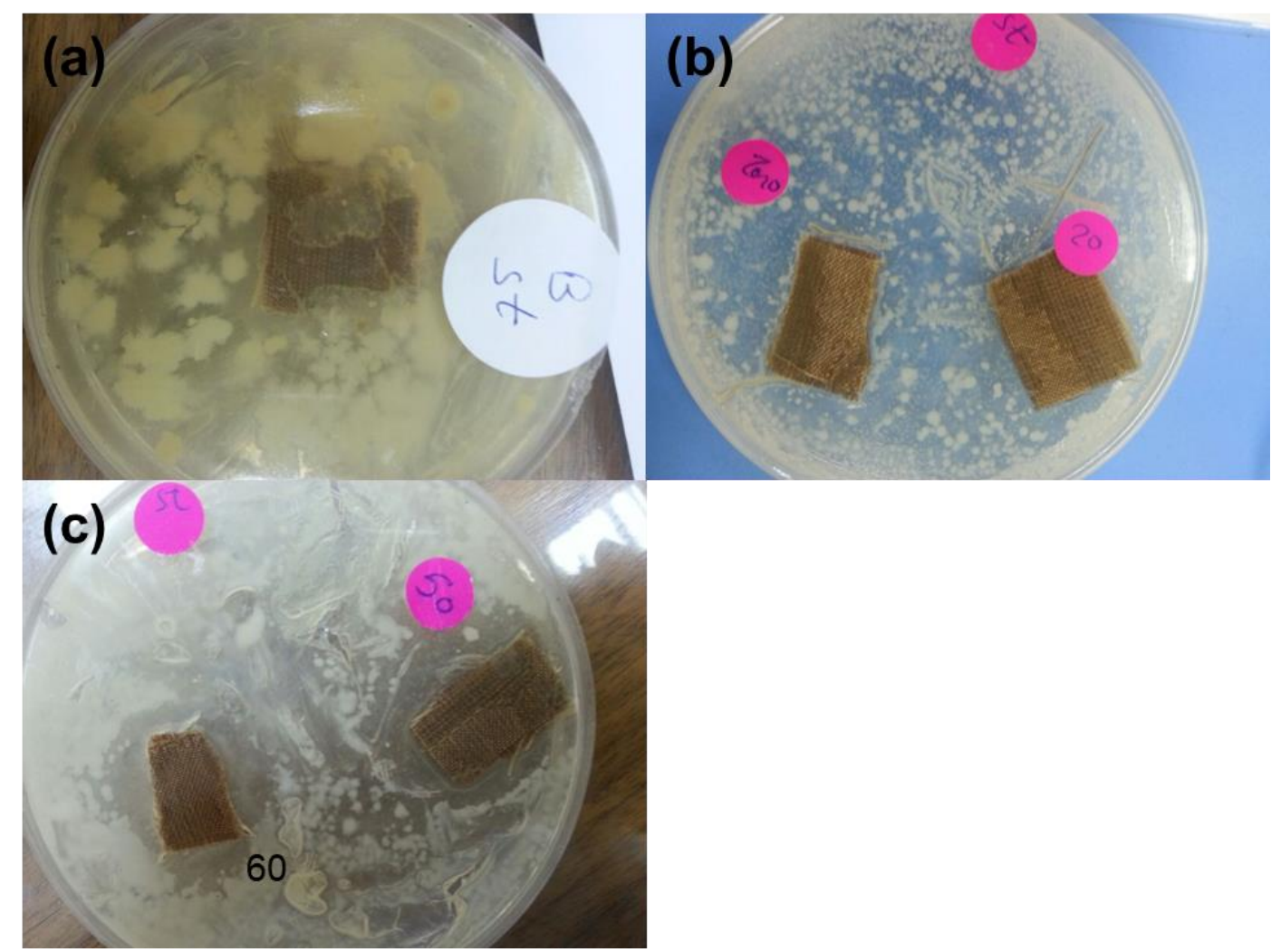

Figure 4. Digital photos of bacterial inhibition zone of (a) $\mathrm{T}$, (b) $\mathrm{T}-\mathrm{CH}$ and $\mathrm{T}-\mathrm{CH}-\mathrm{OA}-20$, and (c) T-CH-OA-50 and T-CH-OA-60.

Table 5. Antibacterial zone of untreated and treated textile fabrics.

\begin{tabular}{cc}
\hline Sample Code & Average Width of Clear Inhibition Zone (mm) \\
\hline T & 0 \\
T-CH & 0 \\
T-CH-OA-20 & 0 \\
T-CH-OA-50 & 12.3 \\
T-CH-OA-60 & 18 \\
\hline
\end{tabular}

\section{Conclusions}

Smart organic antibacterial and charring agent was developed. $\mathrm{N}$-[2,3-dibromo-4-(4-methoxy-3-methylphenyl)-4-oxobutanoyl]anthranilic acid (OA) was facilely synthesized and used as flame retardant, charring, and antibacterial organic agent for textile fabrics. $\mathrm{N}$-[2,3-dibromo-4-(4-methoxy-3-methylphenyl)-4-oxobutanoyl]anthranilic acid was used with chitosan for coating furniture textile fabrics. The mass loadings of developed organic agent was varied and optimized. The coating composite coated on the textile fabrics surface was found in the fiber shape. The thermal stability and char residues of coated textile fabrics were enhanced when compared to blank and chitosan coated samples. Additionally, the flame retardancy was improved achieving $23.8 \%$ LOI and zero rate of burning for developed coated sample as compared to $18.2 \%$ and $118 \mathrm{~mm} / \mathrm{min}$. for blank untreated sample. The tensile strength of the coated textile fabrics was improved by $51 \%$ and $7 \%$ when compared to the uncoated blank and chitosan coated samples, respectively. The antibacterial behavior for the coated textile fabrics included organic agent was positively enhanced recording 
$18 \mathrm{~mm}$ of clear inhibition zone as compared to negative behavior for blank and organic agent free coated samples.

Supplementary Materials: The following are available online at http://www.mdpi.com/20796412/10/6/576/s1, Figure S1: FTIR spectrum (a) and ${ }^{1} \mathrm{H}$ NMR (300 $\mathrm{MHz}$, DMSO) spectrum (b) of 2-[3-(4-Methoxy-3-methylphenyl)-3-oxoprop-1-enyl]-4H-3,1-benzoxazin-4-one (2), Figure S2: FTIR spectrum (a), ${ }^{1} \mathrm{H}$ NMR (300 MHz, DMSO) spectrum (b) and mass spectrum (c) of $\mathrm{N}$-[2,3-Dibromo-4-(4-methoxy-3-methylphenyl)-4-oxobutanoyl]anthranilic acid (3) (OA), Figure S3: Suggested fragmentation pattern of compound (OA).

Author Contributions: Conceptualization, N.F.A. and S.S.E.-S.; methodology, N.F.A.; software, M.H.S.; validation, N.F.A., S.S.E.-S. and M.H.S.; formal analysis, M.H.S.; investigation, N.F.A.; resources, S.S.E.-S.; data curation, M.H.S.; writing—original draft preparation, N.F.A.; writing—-review and editing, N.F.A.; visualization, N.F.A.; supervision, S.S.E.-S.; project administration, M.H.S.; funding acquisition, S.S.E.-S. All authors have read and agreed to the published version of the manuscript.

Funding: This research received no external funding.

Conflicts of Interest: The authors declare no conflict of interest.

\section{References}

1. Singh, M.K.; Varum, V.K.; Behera, B.K. Cosmetotextiles: State of Art; Fiber and Textiles: Łódź, Poland, 2011; pp. 27-33.

2. Foksowicz-Flaczyk, J.; Walentowska, J.; Przybylak, M.; Maciejewski, H. Multifunctional durable properties of textile materials modified by biocidal agents in the sol-gel process. Surf. Coatings Technol. 2016, 304, 160-166. [CrossRef]

3. Malshe, P.; Mazloumpour, M.; El-Shafei, A.; Hauser, P. Multi-functional military textile: Plasma-induced graft polymerization of a $\mathrm{C} 6$ fluorocarbon for repellent treatment on nylon-cotton blend fabric. Surf. Coatings Technol. 2013, 217, 112-118. [CrossRef]

4. Attia, N.F.; Mousa, M. Synthesis of smart coating for furniture textile and their flammability and hydrophobic properties. Prog. Org. Coatings 2017, 110, 204-209. [CrossRef]

5. Hebeish, A.; El-Naggar, M.; Fouda, M.M.; Ramadan, M.A.; Al-Deyab, S.S.; El-Rafie, M. Highly effective antibacterial textiles containing green synthesized silver nanoparticles. Carbohydr. Polym. 2011, 86, 936-940. [CrossRef]

6. Xu, Q.; Xie, L.; Diao, H.; Li, F.; Zhang, Y.; Fu, F.; Liu, X. Antibacterial cotton fabric with enhanced durability prepared using silver nanoparticles and carboxymethyl chitosan. Carbohydr. Polym. 2017, 177, 187-193. [CrossRef] [PubMed]

7. El-Shafei, A.; Okeil, A. ZnO/Carboxymethyl chitosan bionano-composite to impart antibacterial and UV protection for cotton fabric. Carbohydr. Polym. 2011, 83, 920-925. [CrossRef]

8. Attia, N.F.; Morsy, M.S. Facile synthesis of novel nanocomposite as antibacterial and flame-retardant material for textile fabrics. Mater. Chem. Phys. 2016, 180, 364-372. [CrossRef]

9. Cheema, H.; El-Shafei, A.; Hauser, P.J. Conferring flame retardancy on cotton using novel halogen-free flame retardant bifunctional monomers: Synthesis, characterizations and applications. Carbohydr. Polym. 2013, 92, 885-893. [CrossRef]

10. Hassan, M.; Hammoda, H.; Salah, A.; Attia, N. Thermal Analysis Techniques as a Primary Sign for Fire Retardancy of New Textile Back-coating Formulations. J. Ind. Text. 2010, 39, 357-376. [CrossRef]

11. Elashery, S.E.A.; Frag, E.Y.; Mousa, M.G. A comparative study of tetra-n-butylammonium bromide potentiometric selective screen printed, carbon paste and carbon nanotube modified graphite sensors. J. Iran. Chem. Soc. 2019, 17, 911-921. [CrossRef]

12. Liu, Y.; Zhao, J.-C.; Zhang, C.-J.; Cui, L.; Guo, Y.; Zhu, P.; Zhang, H.; Zheng, Z.-W.; Wang, D. Flame retardancy and thermal degradation properties of cotton/alginate fabric. J. Therm. Anal. Calorim. 2016, 127, 1543-1551. [CrossRef] 
13. Xu, Q.; Ke, X.; Shen, L.; Ge, N.; Zhang, Y.; Fu, F.; Liu, X. Surface modification by carboxymethy chitosan via pad-dry-cure method for binding Ag NPs onto cotton fabric. Int. J. Boil. Macromol. 2018, 111, 796-803. [CrossRef]

14. Attia, N.F.; Moussa, M.; Sheta, A.M.; Taha, R.; Gamal, H. Effect of different nanoparticles-based coating on the performance of textile properties. Prog. Org. Coatings 2017, 104, 72-80. [CrossRef]

15. Mathew, B.P.; Kumar, A.; Sharma, S.; Shukla, P.; Nath, M. An eco-friendly synthesis and antimicrobial activities of dihydro-2H-benzo- and naphtho-1,3-oxazine derivatives. Eur. J. Med. Chem. 2010, 1502-1507. [CrossRef] [PubMed]

16. Elashery, S.E.; Attia, N.F.; Omar, M.M.; Tayea, H.M. Cost-effective and green synthesized electroactive nanocomposite for high selective potentiometric determination of clomipramine hydrochloride. Microchem. J. 2019, 151, 104222. [CrossRef]

17. Habib, O.M.O.; Hassan, A.E.-M.H.M.; Hassan, H.M.; El-Meka, A. Studies on Some Benzoxazine-4-one Derivatives with Potential Biological Activity. Am. J. Org. Chem. 2012, 2, 45-51. [CrossRef]

18. Khan, Z.A.; Naqvi, S.A.R.; Shahzad, S.A.; Mahmood, N.; Yar, M.; Zahoor, A.F. Synthesis and Antimicrobial Activity of 2-Aryl-4H-3,1-benzoxazin-4-ones. Asian J. Chem. 2013, 25, 152-156. [CrossRef]

19. El-Hashash, M.A.E.-A.; Azab, M.E.; Faty, R.A.E.-A.; Amr, A.E.-G.E. Synthesis, Antimicrobial and Anti-inflammatory Activity of Some New Benzoxazinone and Quinazolinone Candidates. Chem. Pharm. Bull. 2016, 64, 263-271. [CrossRef]

20. Deshmukh, M.; Suryawanshi, A.; Mali, A.; Dhongade, D.S. New Route to Synthesis and QSAR Study of 1,2,4-Aryl Substituted Triazoles. Synth. Commun. 2004, 34, 2655-2658. [CrossRef]

21. Madkour, H. Reactivity of $4 \mathrm{H}-3,1-$ benzoxazin-4-ones towards nitrogen and carbon nucleophilic reagents: Applications to the synthesis of new Heterocycles. Arkivoc 2004, 36. [CrossRef]

22. Nowakowska, Z. A review of anti-infective and anti-inflammatory chalcones. Eur. J. Med. Chem. 2007, 42, 125-137. [CrossRef] [PubMed]

23. Bandgar, B.P.; Gawande, S.S.; Bodade, R.G.; Totre, J.V.; Khobragade, C.N. Synthesis and biological evaluation of simple methoxylated chalcones as anticancer, anti-inflammatory and antioxidant agents. Bioorganic Med. Chem. 2010, 18, 1364-1370. [CrossRef]

24. Sahu, N.K.; Balbhadra, S.S.; Choudhary, J.; Kohli, D.V. Exploring pharmacological significance of chalcone scaffold: A review. Curr. Med. Chem. 2012, 19, 209-225. [CrossRef] [PubMed]

25. Malucelli, G. Sol-Gel and Layer-by-Layer Coatings for Flame-Retardant Cotton Fabrics: Recent Advances. Coatings 2020, 10, 333. [CrossRef]

26. Tadesse, M.; Mengistie, D.A.; Chen, Y.; Wang, L.; Loghin, C.; Nierstrasz, V. Electrically conductive highly elastic polyamide/lycra fabric treated with PEDOT: PSS and polyurethane. J. Mater. Sci. 2019, 54, 9591-9602. [CrossRef]

27. Tadesse, M.; Loghin, C.; Chen, Y.; Wang, L.; Catalin, D.; Nierstrasz, V. Effect of liquid immersion of PEDOT: PSS-coated polyester fabric on surface resistance and wettability. Smart Mater. Struct. 2017, 26, 065016. [CrossRef]

28. Attia, N.F.; El Ebissy, A.A.; Hassan, M. Novel synthesis and characterization of conductive and flame-retardant textile fabrics. Polym. Adv. Technol. 2015, 26, 1551-1557. [CrossRef]

29. Attia, N.F.; Moussa, M.; Sheta, A.M.; Taha, R.; Gamal, H. Synthesis of effective multifunctional textile based on silica nanoparticles. Prog. Org. Coatings 2017, 106, 41-49. [CrossRef]

30. Papa, D.; Schwenk, E.; Villani, F.; Klingsberg, E. ß-Aroylacrylic Acids. J. Am. Chem. Soc. 1948, 70, 3356-3360. [CrossRef]

31. Abdel-Fattah, M.; Soliman, E.; Soliman, S. Synthesis and reactions of 2- [2- (2, 4, 6-trimethylbenzoyl) vinyl] -4H-3, 1-benzoxazin-4-one of expected biological activity. Egypt J. Chem. 1999, 42, 499-516.

32. AATCC-147-Test Method. Antibacterial Activity Assessment of Textile Materials Parallel Streak methods: Parallel Streak Method; American Association of Textile Chemists and Colorists: Research Triangle Park, NC, USA, 2004.

33. ISO Standard Test. Determination of Burning Behaviour of Interior Materials; International Organization for Standardization: Geneva, Switzerland, 1989. 
34. Elsayed, E.M.; Attiab, N.F.; Alshehria, L.A. Innovative Flame Retardant and Antibacterial Fabrics Coating Based on Inorganic Nanotubes. Chem. Select. 2020, 5, 2961-2965. [CrossRef]

35. Dong, C.; He, P.; Lu, Z.; Wang, S.; Sui, S.; Liu, J.; Zhang, L.; Zhu, P. Preparation and properties of cotton fabrics treated with a novel antimicrobial and flame retardant containing triazine and phosphorus components. J. Therm. Anal. Calorim. 2017, 131, 1079-1087. [CrossRef]

(C) 2020 by the authors. Licensee MDPI, Basel, Switzerland. This article is an open access article distributed under the terms and conditions of the Creative Commons Attribution (CC BY) license (http://creativecommons.org/licenses/by/4.0/). 